\title{
Rethinking technology on the boundaries of life and work
}

\author{
Susanne Bødker \\ Department of Computer Science, Aarhus University \\ bodker@cs.au.dk
}

\begin{abstract}
Technology is often seen as seamless, or making (life/work) boundaries go away. Ubicomp design for that, or for seamlessness in general. However, there may be better ways of understanding boundaries, so as to design technologies in the space of changing work/life boundaries, which is the topic of this special issue. This paper makes a theoretical argument to insist that boundaries are not fixed, neither can or should they be made away with technologically, through seamless technologies. Based on this argument it discusses various presumed technology-mediated boundaries of work and home, life, etc., as they can be found in Ubicomp, CSCW and $\mathrm{HCl}$ literature. The paper addresses: The ways in which work and work technologies are stereotypically connected to effectiveness and hard labor, and non-work technologies to fun and enjoyment; the ways in which technologies move back and forth between mediating work activity and non-work; the role of place and time boundaries in relation to the ability to work any time, anywhere and the metaphors used to address these boundaries; the perceived boundaries of private versus public, and the new boundaries created by technologies in and across our lives and work. Using an empirical case the paper offers an alternative use of boundaries as resources to be activated and used in design. I suggest that we need to more carefully design technologies that provide not seamlessness but seamfulness on these specific and dynamic boundaries, and end the paper with a discussion of how.
\end{abstract}

\section{Introduction}

Technology has moved from workplaces to become part of nearly every aspect of everyday life. In some ways, distinction between which activities are work-related and which are not is becoming less and less meaningful, as often the spheres of work and life blur into each other. In my NordiCHI keynote [8], the starting point 
for discussing technology in relation to work and non-work was the observation that much of recent HCI design was more or less grounded on the idea that all the good stuff was the non-work design, whereas design in relation to work was way less exciting and much more old-fashioned. This is well in line with the spirit of the time where 'thinking work' was deliberating itself from the office and the work-floor, and where e.g. Google's set-up became an attractive life-form for many people. I made the point then, that it makes sense to understand better how the non-work design processes and technologies permeate back into work, and not just how we should step out of work and only design for fun.

10-15 years ago when I started studying these phenomena it seemed, in many ways, like a new ideal: that work would move out of its industrial-age, confined times and places, and that for innovative and interesting work situations we would emphasize being 'always on' through technology. Whether we would work at home, in cafés or in fancy open workspaces with access to all our daily needs, from laundry cleaning to 24-7 meal services. In the time period since, technology such as mobile phones, instant messaging and social media have truly blurred the boundaries of specific work vs. non-work situations. Not only can people be reached no-matter where they are or when, in lack of better words, we also use terms such as 'dwelling' and 'home' to understand how office workers e.g. create their own space in a flexible, open office space. The Norwegian gender researcher Kvande [39] talks about boundless time cultures of global knowledge work organizations, and addresses how it seems that control over the work/life boundaries are handed over to the individuals in such organizations: "The organization of work, with the emphasis on individual responsibility and team organization, together with the boundless time cultures, represent a set of strong structural forces in knowledge work. However, the disciplining processes of empowerment and individualization makes the employees themselves the driving force behind the long-hours work culture."

This sets the scene for many, loosely defined kinds of boundaries that this paper discusses further-time and place boundaries, work and life divide, blending of metaphors. In this paper, I'm largely continuing a tradition of thinking in the CSCW field, where boundaries are looked upon as resources $[54,55,41,28,16$, 13] and where technology plays a role in mediating, dissolving, enforcing, changing, negotiating and maintaining boundaries. The scope is our work and life as a whole and the question is how we may understand and work with technologies in this space?

The paper is structured as follows: First an overview of the literature, and of the general theoretical framing of the paper; then discussion of the various kinds of boundaries in the general technology mediated work-life space. This leads to a more detailed discussion of a particular case, and a conclusion. 


\section{Method and background cases}

The current paper is based on a number of case studies that I have carried out over the past years in cooperation with others. These cases in some way or other address the boundaries of work and home, and the technologies within them: People who work from home, and are mobile because they have to work where they are; people who travel between an office and work outside the office; people who work trough micro-mobility in the office or in large plants; people who use work technologies at home or while commuting; and people who use home technologies while at work $[3,4,6,7,9,10,12,19,20]$. Some of the cases also move beyond that, and embrace somebody's work and somebody else's life as e.g. the daily work of municipal care or case workers [13], and on the other the infrequent, yet quite intense use as when families for rather brief but intensive periods of their lives engage with the planning of their parental leave [13, 22, 23, 24]. Several of the cases regard industrial and white-collar work, as well as care work, while some certainly are about the type of work that people like myself (researchers and educators) do.

The research method is realist rather than optimist or pessimist: In the paper I conduct a dialogue with literature, cases from my empirical projects, and other examples, with the purpose of questioning the very idea that there are boundaries between work and the rest of our lives that could or should be maintained or crossed through technology. Finally I discuss one design case for further detail.

\section{Boundaries, work and knotworking}

The current paper starts out from a rather vague and ambiguous understanding of boundaries; largely as a rhetorical move to embrace the many uses of terms such as divides, boundaries and borders, in order to discuss whether these boundaries hold, as phenomena and understanding in the current, technology mediated situation. At the same time, the notion of boundaries is known in literature from Star's notion of boundary objects:

" Boundary objects are objects which are both plastic enough to adapt to local needs and constraints of the several parties employing them, yet robust enough to maintain a common identity across sites. They are weakly structured in common use, and become strongly structured in individual-site use. They may be abstract or concrete. They have different meanings in different social worlds but their structure is common enough to more than one world to make them recognizable, a means of translation. The creation and management of boundary objects is key in developing and maintaining coherence across intersecting social worlds." (Star \& Grisemer [54]),

Boundary objects $[54,55]$ are often (though not actually by Star herself) seen as addressing objects and information that cross boundaries between communities. 
As discussed by e.g. Lee [41], this seems oversimplified, and a "sailing across" boundaries is not all that happens. Boundary drawing and boundary opening, or boundary negation happen continuously and in a dialectical manner. Lee [41] suggests a focus on boundary negotiating artifacts that push or strengthen the boundaries, and Star herself [55] sees boundary objects as a kind of interim objects in standardization and formation of practice. Clement \& Wagner [28] discuss how drawing boundaries are a way of creating more efficient communication within the boundaries, and reducing complexity of collaborative activity by doing so. In continuation of Star [55], boundary objects are important elements in the process of formalizing the sharing on these boundaries.

For the purpose of this paper it may be worth emphasizing that the term work is not only used to talk about paid labor. It is often also used to focus on productive/purposeful activity of many sorts, across paid labor, home care, volunteering, etc. In addition the boundary drawing and opening, as discussed above, require work as such; it requires human activity:

The cultural anthropologist Barth [1] addresses processes, contexts and situations in which are boundaries generated. Barth focuses on boundaries and boundary work rather than "on the cultural stuff that it encloses" ([1] p. 15). In [20] this definition is used to address boundaries and work technology. Pursuing this manner of thinking, boundaries are not stable and Engeström et al. [30, 31] use the notion of knotworking to understand how much of work e.g. in open source communities happens in relatively rapidly emerging and disappearing projects within the frames of complex constellations of organizations without clear-cut boundaries. Knotworking represents dynamically changing and distributed collaborative work processes around objects and purposes that take their own life. These forms of collaboration happen, and change over shorter time, where boundaries are drawn for a time, rather than permanently.

Ubiquitous Computing has, since it was established in the late eighties, has had a great focus on the disappearing computing and seamlessness [29]. Chalmers \& Galani [26] point out that seamless, embodied interaction is mirrored in seamfulness, revealing differences and limitations of the technology. The notion of seamfulness as a resource is a good match with the boundary-thinking presented here, and as pointed out by [26], seamlessness potentially contradicts learning and the ways in which people build their understanding and use over time. In this paper I propose to address technologies as mediators of this ongoing development, parallel to how [26] discuss seamfull technologies rather than seamlessness, where there are no boundaries between uses.

I propose that we need a richer, and more dynamic understanding of boundaries, and I have outlined how Lee's boundary negotiating artifacts, Bath's work on the boundaries and Engeström's knotworking may help in this endeavor. Accordingly, I suggest that we study and understand technologies in the contradiction between boundary drawing and boundary opening, or boundary 
negation as Lee [41] puts it. In human activity, boundaries are dynamic and change over time. They are drawn, challenged and negotiated, and worked on, all the time. They help reduce complexity of the joint activities and may be helped in the technology by seamfulness on the boundaries, in addition to seamlessness within the joint activity as such.

\section{Work-life boundaries}

In the following I will look in more detail at the roles of technologies in relation to what is often seen as boundaries of work and life. I do this by questioning some of the often presumed boundaries: The ways in which work and work technologies are stereotypically connected to effectiveness and hard labor, and non-work technologies to fun and enjoyment; the ways in which technologies move back and forth between mediating work activity, and mediating non-work; the role of place and time boundaries in relation to the ability the work any time, anywhere and the metaphors used to address these boundaries; the perceived boundaries of private versus public, and the new boundaries created by technologies in and across our lives and work.

\subsection{The idealization of the home-boundaries of joy and hard work}

In the industrial age, home and work became separated in time and place, and to some extent, for many it still is, in the industrial and post-industrial society, with the exception of e.g. certain kinds of freelancers, farmers (see e.g. [40]) and others. The separation historically has put a strain on home-life, leading to kids being left at home to care for themselves, and to increasing needs for transportation and other infrastructure. In this sense there is more to life outside work than what happens in the home, and [47] pointed out how the realm outside of work is clearly so complex that it eludes naming and is defined mainly by negations: "Everything but work."

"Home offers as convenient (though probably just as inaccurate) a term as work in referring to a place or state where much of life occurs. Leisure is often understood in contrast to work as well, but this choice of term fails to hold because work serves not only to refer to employment, but also to describe a general state of action that is broader than employment, too. So home serves to be a contrast to "work-as-employment," but homes most certainly not the same as leisure; home is the place for yet other kinds of work." [47]

The paper continues to point out "That work should be effective, while emotions belong to the "rest of life" mirrors ideas that evoke the most old-fashioned Tayloristic conceptions of industrial work, at the same time that work today takes many other forms." The paper points out how home/family life seems overidealized. It uses the examples from Hochschild's [35] discussions of how, in an industrial labor setting, some American parents try to escape the time trap (and 
emotional turmoil) of home with its complex and aggravating scheduling requirements, by spending more hours at work, where at least they can lean back and have a coffee. Bødker \& Grönvall [13] discuss the idealization of home as something of a particular nature that is 'a castle' under control, leaving nobody in, who are not wanted, and where what happens is harmony and joy. The discussions of what it means to bring into the home professional caregivers, in a situation where a vulnerable elderly needs more care than what can be provided by the immediate relatives or co-inhabitants, points towards many frustrations and little joy on the family as well as the professional side. Hard planning, emotional turmoil and hardship rather than joy and fun seem to penetrate modern home life, as is also the case when it comes to expecting parents: "At the same time parental leave takers see themselves as in a situation of hardship" [24] conclude. Families with newborns express that they are making sacrifices for each other and their child. They use other parents in similar situations to ease this trouble and to share experience; hence opening the boundaries of the home to others in a similar situation.

Sohn et al. [53], and several others have specifically studied how efficiency, for instance is not only a concern for work life, but also for making home life happen through e.g. everyday coordination. In line with [8] these examples point out that work is not per definition unpleasant and home fun, and hence that this way of drawing boundaries between work and home is ill-perceived if not slightly dangerous when it comes to addressing technology: In terms of technology, planning and negotiation of work shifts (both at work and in the home) seem to have moved away from Taylor's and Ford's factory floors and into the home. This is not so much because the work technology as such has penetrated the work-life boundary as it is because handling life as such has become logistically complex. To some extent work technologies such as shared calendars actually help handle this complexity, at the same time as it obviously adds to it. What does it take to rethink technology in this space?

It is often discussed how 24-7/always-on thinking has made work emails intrusive upon home activities, and how providing people with work cell-phones is a way of extending people's work reach ad infinitum outside office hours $[6,9,10]$. People can be more easily reached, with sad as well as joyous messages and calls from home, while at work as well as (what is most often discussed) with work when home. These may disturb people's efficiency, or calm, whether in one location or the other. Many challenges arise that could be treated technologically in better ways: There could indeed be better ways of having multiple, though overlapping identities, or different granularities of indicating availability and unavailability [5] that would be a matter of drawing boundaries in new ways in this multitude of settings with multiple groups, communities or 'friends,' across work and life. Or, to borrow from the seamless/seamful discussion in Ubicomp [26], it could be worthwhile to consider not ways of making the technology seamless on the boundary between one setting and another, but to actually provide better seamfulness to control such various boundaries. 


\subsection{Work from home, and home-place boundaries}

As people most often live in one place and work on another, there are various ways in which the commute and the homes have become places of work, in order for people to best utilize their time and reduce the costs of traveling. The cost of traveling as such has become an item of concern, as demonstrated in Jönsson's discussion of time [37]. In addition, work for many people is distributed. This may either be because sites of various kinds may need to be visited for inspection, repair, etc. (see e.g. [38,45]), or because work is dependent on collaboration with distant collaborators, such as what is often the case in project work of different kinds. Luff and Heath [42] have talked about 'remote mobility', i.e. where mobility workers move or travel across larger distances. Technologies have been studied to support cooperation between mobile workers moving around or traveling (e.g., [57, 58]). Nomadic work has been introduced as a term for certain forms of mobile work $[56,6,51]$ with inspiration from nomadic travels of people who depend on food for their cattle etc. and largely move their home as well as their work depending on season, etc. Whether or not this is an appropriate metaphor, is a good question. However, Su \& Mark [56] describe how nomadic work has become prevalent in modern organizations, and point towards a competition for resources that is quite similar to the classical nomads. Recently we have, in Scandinavia, seen the rise of a Hoffice movement (http://www fastcoexist.com/3041322/hoffice-turns-your-apartment-into-a-freeand-incredibly-productive-coworking-space) whereby freelancers use social media to gather and work in somebody's home that is then turned into an office for the day. And not only that, they work in structured 45 minutes shifts that they commit to, seated at kitchen tables and on the couch or whatever is available.

A particular challenge, which is for a different sort of work than these freelancers, is traveling to work in locations that are somehow not open and friendly to the visitor, such at the Labor Inspectors, who need to produce inspection reports on sites, sometimes after having stopped some work due to health hazards for the workers [19]. In these cases, asking to print on location, or even use the wifi may not be appropriate and a result of boundary negotiation, making visible seams important. Su \& Mark [56] mention etiquette, ergonomics and privacy as important elements of design for technologies in settings where people move about, and work in ad hoc settings, is some sort of competition with others. In these kinds of settings, accordingly the boundary-drawing may not be about home or not home, but about e.g. friendly or hostile settings of work, about different structures and routines than what workplaces normally offer, about being alone or together with others while working, or about privacy, as I'll return to.

With this kind of mobile work, people inevitably bring technologies, and work, home, if only for the practical reason of the driving distance being shorter if going home directly. Work technologies (e.g. calendars or email) largely offer themselves to being used not only in the home, but also for non-work purposes. Many freelancers are dependent mainly on their (one) PC and their cell-phone, 
and the nomadic workers may even bring technologies from one workplace to the next, and have a need to make the technologies they bring connect to some of those that are already there. In this sense the technology basically mediates everything they do, and it may even be the most persistent tool they have. This kind of persistency is discouraged by security experts but encouraged by suppliers of technology and e.g. many Danish cell-phones come with a subscription to music streaming, etc., inviting to be used for leisure, and also to not put the phone away, when seemingly outside work. A central question has become how people do not work when their home is full of work technologies? How may the technologies themselves help them manage these boundaries. And vice versa, how do they not bring home to work and shield their home off through their smartphones, etc.?

\subsection{Life as connecting work-temporal boundaries and metaphorical blends}

Sennett [52] discusses the individualization and the temporary nature of work (moving from one job to the other). The dependency on individual contacts and connections is a concern in flexible organizations as well as when moving from one job to the other [36]. [25] as well as [6, 9, 10, 12] discuss the open office where people have no permanently assigned desk, but where they (perhaps they work in other places much of their time)only have an office for the day ('hotdeskers') or work in designated 'touch down' areas or cafés. In 2004, the predominant spaces to design for [34], were those of café, club and cloister, according to the well-known open space office architects, DEGW, nicely borrowing their metaphors for the world outside work. Bødker \& Christiansen [12] in parallel talk about what they call dwelling, and point out that it is important to dwell in order to develop routines and to learn. Accordingly, the metaphor of dwelling [12] means that one is able to move and come back, to repeat what one is doing. To have an environment that is recognizable is an element of developing routines, and routines, even in the flexible work setting is a precondition for legitimate participation (similar to one of the concerns of $\mathrm{Su} \&$ Mark [56]). Obviously again, the technologies people carry with them are essential to this, but so is e.g. recognizing the possibilities of easily linking to Wifi, large screens etc. in smooth and largely seamless manners, while also making sure (the privacy concern) that not to leave electronic traces and materials behind when leaving, hence at some point breaking away from the seamlessness. In the studies of Bjerrum \& Bødker [8], as well as Brown \& O'hara [25], one reason for hotdeskers and mobile workers to spend time in recognizable locations in the office place is to make themselves available for interaction with others, be they metaphorical cafés, clubs or not. At the same time, open and non-permanent office spaces occationally appear chaotic, and real cafés are then used also as meeting space and as places to get work done [32], away from the chaos of the office. Engeström's notion of the knot rather than the net [30] points to the temporal interconnectedness of people, tasks and technologies, posing challenges to boundary-drawing and technologies, as these knots come and go over time. 
In terms of technology, the notion of dwelling is a way of addressing learning and development of routines in work contexts that are physical flexible, and even turbulent. Technology that supports this kind of dwelling is also then supporting boundary work in new, perhaps more temporary configurations of workers, in a particular location. However, there seems to be a long way to go before the technologies help us make and change these set-ups to make us available, or unavailable, when we dwell in different places, and not least activities. While this challenge is far from new [9], we lack both concepts and technologies that help people draw, negotiate and shift boundaries in manners that are not ad hoc, and hence help them learn and develop routines as part of knotworking and boundary work. The focus on new routines, boundary drawing and technological seamfulness over time, is accordingly, designwise, a necessary step away from the all-open, seamless chaos that current technologies have been instrumental in creating.

\subsection{Home as the place for work-public-private boundaries}

The home may be the place to escape to, or the framing of hard work, but it is more than that. There are ways in which the home as such becomes a professional frontstage [43, 49], just like the home (for some) has always been the workplace for others. Bødker \& Grönvall [13] discuss what happens when work in the home is no longer just a matter of domestic work of various sorts, and it becomes the hub and meeting place for various groups of professional health workers as well as a distributed family. When professionals step into the home of people who are ill and need care, this may at times take the control of the space out of the hands of the owner and even the relatives $[27,33]$.

When doing field studies and design work with international, very wealthy people, Lynggaard [43] points out that many of them have several homes that they move between. These are necessarily staffed to make this smooth moving about happening, and they serve, due to the nature of the work of these people, as much as work and as home: "The dualistic side to the homes, being the homely part on one hand and the public home on the other hand makes it a complex environment to live in. It is home but at the same time it is work. It is so large that there is a need for private zones. The domestic chores are highly outsourced and there is a sense of effort in running the house that can be compared to running a company." [43]

In several instances, the privacy zones are not enough for these people to escape working to run the house, and at times they escape to hotels to find the privacy, which they cannot have at their home(s). This illustrates that even in the home, the concern is with the drawing, shifting and negotiating of boundaries, and the many ways in which technologies may or may not support this. Accordingly, the immediate boundary connection between home and private does not hold. Graves Pagter \& Petersen [46] discuss this kind of privacy when they discuss how 
travelling businessmen make hotel rooms their own for short periods of time. The boundary work to address privacy is not as such related to the home, which may not as such be surprising. It is yet another example where the metaphors need to be questioned when we design and consider technologies mediating these boundaries:

Birnholtz et al. [5] not only borrow metaphorically from the home when they talk about the role of butler as protector of availability and privacy in the classical home. The notion of 'Butler lies' are used in understanding and designing for how people may make themselves unavailable, and the paper touches upon the problem that such unavailability is not universal, but highly dependent on who is asking, i.e. the boundary making in and among groups of friends and acquaintances: "Clear threats to the plausibility of butler lies may affect not only whether the lie is successful, but also the relationship itself. Social media tools such as Facebook and Twitter further complicate matters by not making it clear who has seen or has access to certain information (e.g., specific status updates, tweets, etc.). We therefore urge designers to consider ways to make it clear who has access to and has seen specific bits of information about others. This would allow people to better understand what others know, and construct explanations more likely to be effective".

Now only is work and life intertwined. It is intertwined partly because some people's lives are other people's work, which as illustrated adds issues of privacy to boundary work, and the technologies on the boundaries.

\subsection{New, technology-created boundaries across life}

There are other ways in which the boundaries of the family and the homes are being negotiated and adjusted partly through technologies otherwise mainly known from work (e.g. [48]). Monitoring and controlling of children through cellphone is one of these [59]. Bødker \& Christiansen [11] discuss the ways that the iPhone bridges between work and life: Several of their interviewees mention as an expectation to their new iPhone to get a better mobile organizer/calendar across work/school and life: "I got the phone trough work. We wanted a shared calendar for four of us, and perhaps later for the entire school. We put phone numbers of all students on the phones, and that has turned out to be really useful for me as study counsellor. The shared calendar was less successful, but in other ways the iPhone is highly addictive." "The iPhone has changed my life because it is just so easy to check little things on the web. I check my school schedule and assignments several times during the day. "

Recent technologies for various forms of sharing, such as Uber, airbnb and nonprofit timebanks $([2,44])$ have popped up in the technological landscape. By allowing people to share rides or do jobs for each other, they cut across work and life in ways that are challenging to general thinking, public authorities and insurance agencies. News stories across the globe question Uber's legitimacy. 
Whether the driver offers a ride to somebody for a trip he had to make anyway, or he offers to 'taxi' somebody, makes a big difference to e.g. legislation, and illustrates the fuzzy boundaries between work and life (see e.g. http://www theverge.com/2014/12/9/7359655/uber-banned-in-spain-india-andthailand-due-to-illegal-operations). Our lives with these new social technologies have not yet found a place in legislation and the lack of standardized understanding of what they are challenging across community boundaries, at the same time, of course, as they question existing ones.

\subsection{How to deal with technologies on work-life boundaries?}

In the above, I have discussed the ways in which work and work technologies are stereotypically connected to effectiveness and hard labor, and non-work technologies to fun and enjoyment; the ways in which technologies move back and forth between mediating work activity, and mediating non-work; the role of place and time boundaries in relation to the ability the work any time, anywhere and the metaphors used to address these boundaries; the perceived boundaries of private versus public, and the new boundaries created by technologies in and across our lives and work. I have suggested that we need to learn from these boundaries but not take them for granted as static. Recent on-line services are e.g. challenging and pushing the boundaries, as well as the perception of what is work and what is not. However, the above section has pointed out that it is NOT the work/life boundaries as such that we need to be concerned with as much as we need to be concerned with how specific boundaries are managed and changed through specific technologies.

I suggest that we need to address how the change and negotiation of boundaries can be visible and under control of the people using the technologies. I propose to address technologies as mediators of this ongoing development, parallel to how Chalmers and Galani [26] discuss seamfull technologies. Seams, and boundaries, in this view are not static and they are actual resources rather than trouble or borders to be crossed or overcome. No matter work or life at large, there are basically four important reasons for this kind of boundary drawing that need to be considered in our ubiquitous technologies:

1. to support privacy (for individuals as well as groups, as it develops over time);

2. to support the reduction of complexity of information and activity;

3. to standardize objects that are shared across communities and groups;

4. to use boundaries to let groups and communities define themselves, and distinguish themselves from others.

In the next section I will pursue a case to explore future forms of technological mediation of boundary management and negotiation. 


\section{Some people's life and other people's work-more complicated technology mediated boundaries}

The CaseLine study addressed the interaction and collaboration involved in the planning and control of parental leave in a Danish municipality. Such planning involves several citizens (the parents), a municipal office and several other stakeholders such as the parents' employers and labor unions [13, 20, 22, 23, 24]. This parental leave planning process is typically a product of the negotiation between the parents and the surrounding stakeholders, focusing on how the parents may use their rights for parental leave, as determined by national legislation and managed by the municipality, while making the most of the payment that either parent get from their employers, and getting the most out of their leave time. The legislation constrains this planning in particular since the rights of the parents are interwoven with one-another, as are e.g. the parents' vacation rights and agreements with each employer, if there is one. The rules also depend on whether both parents have paid work, or whether one or both are students, self-employed or unemployed. Establishing the best possible solution, in terms of total leave-time, split between mother and father, total income during the leave period, the possibility of spending leave-time together, and saving leavetime for later, calls for the consideration of various "what-if" scenarios. Parents often do not have all the information necessary to calculate these scenarios, and the legislation is difficult to work with due to its inherent flexibility. The municipal office is an important source of advice on this as well as it is approving the final plan.

The planning period for parental leave is up to nine years, which is the child-age when all parental leaves should have been used. Even when parents have decided on the best solution, this has to be communicated to, and negotiated with the respective employers. Moreover, despite having settled on even the best of plans, parents may desire to change their plan. Over the nine-year period, many events may happen that make a change of plans necessary: New jobs, additional children, etc. Consequential changes need to be reiterated with all of the above stakeholders. [20] describes the many challenges of joint parental leave planning, suggests a design concept and present some early prototypes for CaseLine, a timeline/calendar based planning and overview tool to be shared between parents, and towards employers and public authorities (Figure 1). In CaseLine, the municipality can provide general plan elements on-line. These elements may be tailored by e.g. employers and unions, and used by parents as basis for their agreement with the municipality, or by each parent in their agreement with their employer. 


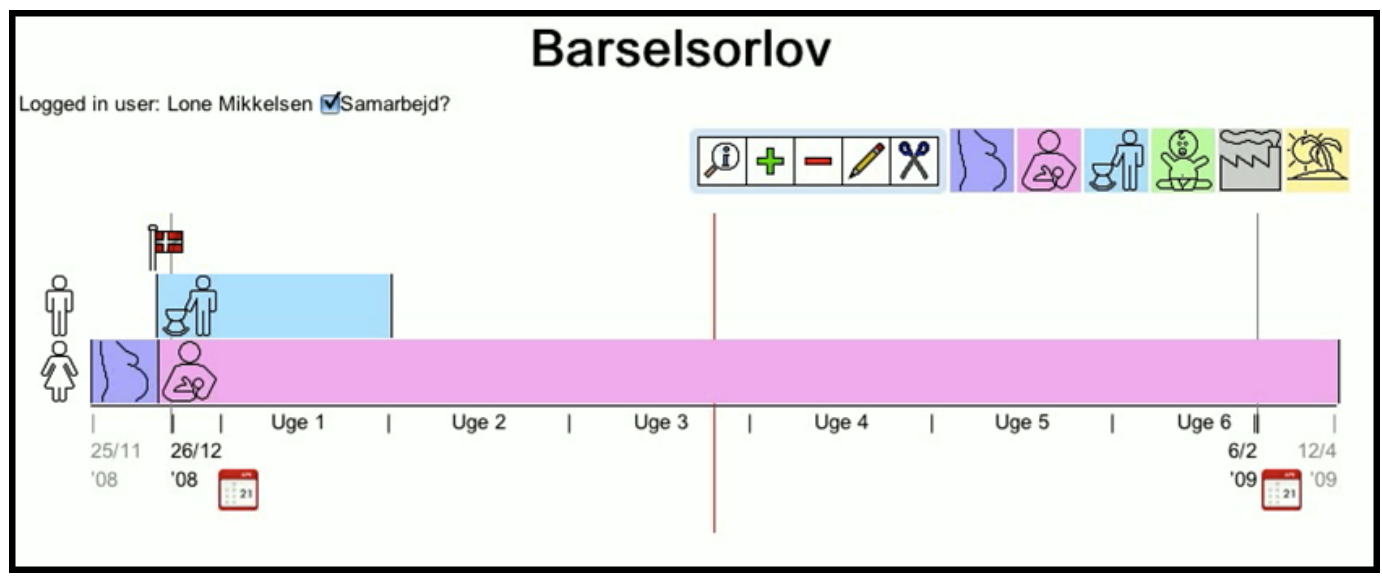

Figure 1. CaseLine provides a timeline-based interface to parental leave plan objects. It supports and facilitates sharing and seamless exploration between parents, at the same time as it supports controlled, seamful sharing with the municipality, when parents allow access to their plan.

It is important for all parties to be explicitly aware of when a certain timeline gets shared and with whom, which illustrates the need to draw boundaries in the specific sharing, or to create a seamfull solution. It is important to understand when the plan/timeline is approved and hence binding, leading to a changed status on the boundaries; a result of negotiating a seam through a formal application.

In addition, since each parent's current employer is responsible for handling the payment of the parental leave salary, as well as they are the ones to let go of their employees for certain, more or less convenient time periods, they are also involved in the planning. In general the parties have different interests in this. For the citizens, it is important to get most money and the optimal plan out, defining their boundary work towards the municipality and their current employers; for the civic servants, the main interests relate to giving everybody equal and transparent treatment, which as such creates tensions and reinforcement of boundaries (with the particular parents and with citizens at large). Indeed, both citizens and municipal workers need to withhold information from each other (draw boundaries and understand what they are), not sharing "everything". Employers are (and should only be) concerned with the time and income of one period, and only for the time that the parent works with them, and not later when the parent has moved to a new job. As parental leaves happen over so long, parents may change employers, and hence, it is necessary to draw a boundary with past employers as time passes. Consequently, the citizens needs to be able to make a clear distinction between exploring possibilities and sharing information (across boundaries) with other stakeholders such as employers and the municipality, where the need for seamfulness comes in.

The possibilities of technologies on these boundaries were explored through a prototype (as discussed by [13]) addressing the citizen strategies to information 
sharing in complex and changing constellations of actors, as well as the dynamic configuration of boundaries necessary to control changing needs for information sharing across time. This support of boundary management and information sharing helps address the tension between the motives of the collaborating actors, essentially, by rendering these motives more comprehensible to the involved actors, hence facilitating boundary work. In this particular case, the time-frame of the citizens is quite different from that of the case workers: Whereas the case workers, and most employers, treat many parental leave plans, and the rules behind them every day, and case workers are mainly concerned with the advice they give for a here-and-now decision, which is then documented and filed for the next time a change needs to happen; for the parent, the child-birth, the leave is a unique experience that changes their life $[22,23]$ and happens very few times in their lives. In accordance with that, Caseline was set up to support a shared understanding of the rules and procedures of the involved actors, while also yielding a shared understanding of the ultimate outcome of the process, parental leave timing and financing, at the same time as it allowed parents to do exploratory planning without sharing this with the case workers or employers until they explicitly decided to.

Caseline took its starting point in the specific boundary-drawing, maintenance and negotiation happening in the parental leave planning, rather than in preassumed boundaries of work and life, place, communities, or time. Caseline mediates knotworking where a particular configuration of caseworkers, parents and employers make decisions about a plan at a particular point in time. It is perhaps not a run-away object exactly as Engestöm describes it, but it is certainly an object that, over time is barely under some specific agent's control: Caseline mediated the exploration and sharing of versions of the plan by the parents over time, with changing collaborators and concerns, i.e. it mediates the transformation of the knotworking, but with the insights from the current paper, it could certainly have been designed to better mark these transformations, and to mark who currently controls it, to provide more seamfulness. Caseline is one example where boundary drawing and boundary opening, or boundary negation happen continuously, over many boundaries. This happens in a space between continuation, where, over time, they bring experiences and artifacts from one activity setting to the next, and disruptions where boundaries are created to reduce complexity and shield off one activity setting to another. It is obvious that in this case boundary drawing is needed both for privacy (though not necessarily individual privacy) and in order to reduce complexity [28].

\section{Redoing technologies on boundaries}

In this paper I question work/life boundaries that seem to be presumed in literature, and more than that I propose that general boundaries as they are considered in this field are harmful and problematic, when it comes to designing 
technologies. How do technically controllable dynamic boundaries play into this, and what can we do in terms of design for such technological settings?

Currently we can indeed say that, while obviously there are some technologies that are used more for work, and some that are more for home, the technology as such largely has no boundaries (in terms of work and life). Systematic and careful attention to the dynamics on the specific boundaries is needed to ultimately counteract the idea that seamlessness and boundarylessness of technologies is what is needed.

As summary of the above examples, I propose that we need to address boundaries as specific and dynamic, conceptually and in relation to design of ubiquitous and collaborative technologies. No matter work or life at large, there are basically four important reasons why this kind of boundary drawing needs to be considered in ubiquitous technologies:

1. to support privacy (for individuals as well as groups, as it develops over time);

2. to support the reduction of complexity of information and activity;

3 . to standardize objects that are shared across communities and groups;

4. to use boundaries to let groups and communities define themselves, and distinguish themselves from others.

This has implications for design, both for the design processes in which boundaries and seamfulness need attention, and for the technologies as such. Based on the above analyses I suggest that we need to more carefully design technologies that provide not seamlessness but seamfulness on these specific and dynamic boundaries:

1. Since technologies support different activities with different people, to help seamfully mark the boundaries between these activities, in particular as they develop over time (knotworking).

2. To help users (individually and together) understand, control the change of collaborators over time, hence helping communities work on the boundaries to define themselves.

3. To provide possibilities for seamfully marking places where activities happen.

\section{Acknowledgements}

\section{References}

1. Barth. F. (1969). Ethnic Groups and Boundaries. Boston: Little, Brown 
2. Bellotti, V. Cambridge, S., Hoy, K., Shih, P.C., Handalian, L.R., Han, K. and Carroll, J.M. 2014. Towards community-centered support for peer-to-peer service exchange: rethinking the timebanking metaphor. In Proceedings of the SIGCHI Conference on Human Factors in Computing Systems (CHI '14). ACM, New York, NY, USA, 2975-2984.

3. Bertelsen, O. \& Bødker, S. (2002). Interaction through multi-artifacts. In Bagnara, S., Pozzi, S., Rizzo, A. \& Wright, P. ECCE 11 - Cognition, Culture and Design Eleventh European Conference on Cognitive Ergonomics, Rome: Instituto di scienze e technologie della cognizione consiglio nazionale delle ricerche, pp. 103-111.

4. Bertelsen, O.W. and S. Bødker (1999): Cooperation in Massively Distributed Information Spaces. In S. Bødker, M. Kyng and K. Schmidt (eds.): Proceedings of the Sixth European Conference on Computer Supported Cooperative Work. Copenhagen, Denmark: Kluwer Academic Publishers, pp. 1-17.

5. Birnholtz, J., Hancock, J., Smith, M. and Reynolds. L. 2012. Understanding unavailability in a world of constant connection. interactions 19, 5 (September 2012), 32-35.

6. Bjerrum, E. \& \& Bødker, S. (2003). Knowledge sharing in the "new office" - possibility or problem? K. Kuutti, E. Karsten G., Fitzpatrick, P. Dourish, K. Schmidt (eds). Proceedings of the Eighth European Conference on Computer Supported Cooperative Work, 14-18 September 2003, Helsinki, Finland, pp. 199-218.

7. Bjerrum, E. \& Nielsen, O. (2003). Bliver man lidt småsær af at have sit eget kontor? JyllandsPostens Erhvervsklub (In Danish: Does having your own office make you slightly mad?)

8. Bødker, S. (2006). When second wave HCI meets third wave challenges. ACM International Conference Proceeding Series; Vol. 189. Proceedings of the 4th NordiCHI, ACM, pp. $1-8$.

9. Bødker, S. \& Christiansen, E. (2004). Designing for ephemerality and prototypicality. Proc. DIS 2004, ACM, pp. 255 - 260, 2004.

10. Bødker, S. \& Christiansen, E. (2006). Computer support for social awareness in flexible work, Journal of CSCW, 15 (1), pp. 1-28.

11. Bødker, S. \& Christiansen, E. (2012). Poetry in motion-appropriation of the world of Apps. Proc. ECCE 2012.

12. Bødker, S. \& Christiansen, E., (2002). Lost and Found in Flexibility, IRIS 2002

13. Bødker, S. \& Grönvall, E. (2013). Calendars: Time coordination and overview in families and beyond. ECSCW 2013.

14. Bødker, S. \& Klokmose, C. N. (2011). The Human-Artifact Model - An Activity Theoretical Approach to Artifact Ecologies. Human-Computer Interaction. Taylor \& Francis. Volume 26, Issue 4, 315-371.

15. Bødker, S. and Klokmose, C.N. 2012. Dynamics in artifact ecologies. In Proceedings of the 7th Nordic Conference on Human-Computer Interaction: Making Sense Through Design (NordiCHI '12). ACM, New York, NY, USA, 448-457.

16. Bødker, S. \& Petersen, A. B. (2007). Seeds of cross-media production, Journal of Computer Supported Cooperative Work, 16:539-566, 2007.

17. Bødker, S. and Polli, A.M. Between initial familiarity and future use: A case of collocated collaborative writing. Proc. COOP 2014, Springer (2014), 137-154.

18. Bødker, S. Polli, A.M. Korn, M. and Klokmose, C.N. (2014). Participatory IT in Semi-Public Spaces. NordiCHI.

19. Bødker, S., Christiansen, E., Ehn, P., Markussen, R., Mogensen, P. \& Trigg, R. (1991). Computers in Context. Report from the AT-project in progress. Arbejdets Udvikling, Proceedings of NES/SAM, pp. 153-158.

20. Bødker, S., Kristensen, J. F., Nielsen, C. \& Sperschneider, W. (2003). Technology for Boundaries. In Proceedings of GROUP'03, ACM Press, pp. 311-320. 
21. Bohøj, M., N. G. Borchorst, N. O. Bouvin, S. Bødker and P.-O. Zander (2010). 'Timeline collaboration'. In Proc. of the 2010 SIGCHI Conference on Human Factors in Computing Systems, ACM Press, p. 523-532.

22. Bødker, S., Korsgaard, H. \& Saad-Sulonen, J. (in press) `A Farmer, a Place and at least 20 Members': The development of Artifact Ecologies in volunteer-based Communities, CSCW 2016.

23. Borchorst, N. G. and S. Bødker (2011): "You probably shouldn't give them too much information" - Supporting Citizen-Government Collaboration, In Proc. of the 2011 European Conference on Computer Supported Cooperative Work, Springer London, p. 173-192.

24. Borchorst, N., S. Bødker and P.-O. Zander (2009): 'The boundaries of participatory citizenship', In Proc. of the 2009 European Conference on Computer Supported Cooperative Work, Springer London, p. 1-20.

25. Brown, B. and O'Hara, K. 2003. Place as a practical concern of mobile workers. Environment and Planning A 35, 9, 1565-1587.

26. Chalmers, M. and Galani, A. (2004). Seamful interweaving: heterogeneity in the theory and design of interactive systems. In Proceedings of the 5th Conference on Designing interactive Systems: Processes, Practices, Methods, and Techniques. DIS '04. ACM, New York, NY, 243252.

27. Christensen, L. R. and E. Grönvall (2011): 'Challenges and Opportunities for Collaborative Technologies for Home Care Work'. In Proceedings of the 12th European Conference on Computer Supported Cooperative Work, 24-28 September 2011, Springer, p. 61-80.

28. Clement, A. and I. Wagner (1995). 'Fragmented exchange: disarticulation and the need for regionalized communication spaces'. In Proc. of the 1995 European Conference on ComputerSupported Cooperative Work, Kluwer, p. 33-49.

29. Dourish, P. (2001). Where the Action Is: The Foundations of Em-bodied Interaction. Cambridge, MIT Press.

30. Engeström, Y. (2005). Knotworking to Create Collaborative Intentionality Capital in Fluid Organizational Fields, Advances in Interdisciplinary Studies of Work Teams, 11, 307-336.

31. Engeström, Y. (2007). From communities of practice to mycorrhizae. In J. Hughes, N. Jewson \& L. Unwin (Eds.), Communities of practice: Critical perspectives. London: Routledge.

32. Greenbaum, J. 2010. Situations and interactions: digital café squatting and participatory design. In Proceedings of the 11th Biennial Participatory Design Conference (PDC '10). ACM, New York, NY, USA, 243-246.

33. Grönvall, E., P. Marti, A. Pollini, A. Rullo and O. W. Bertelsen (2005). 'Palpable time for heterogeneous care communities'. In Proceedings of the 4th decennial conference on Critical computing: between sense and sensibility, ACM Press, p. 149-152.

34. Harrison, A., Wheeler, P. \& Whitehead, C. (2004) The Distributed Workplace: Sustainable Work Environments, DEGW.

35. Hochschild, A.R. The Time Bind: When Work Becomes Home and Home Becomes Work. Metropolitan Books (1997)

36. Huysman, M. and Wulf, V. (2005). The Role of Information Technology in Building and Sustaining the Relational Base of Communities. The Information Society, Vol. 21, Iss. 2, 2005

37. Jönsson, B. (1999). Tio tankar om tid. Brombergs (In Swedish: Ten thoughts about time)

38. Kristoffersen, S. and F. Ljungberg (1998) "MobiCom: Networking dispersed groups," Interacting with Computers, Vol. 10, No., p. 45-65.

39. Kvande, E. 2009. Work-Life Balance for Fathers in Globalized Knowledge Work. Some Insights from the Norwegian Context, Gender, Work \& Organization, 16(1). Blackwell Publishing Ltd 
40. Leshed, G., Håkansson, M. and Kaye, J. 2014. "Our life is the farm and farming is our life": home-work coordination in organic farm families. In Proceedings of the 17th ACM conference on Computer supported cooperative work \& social computing (CSCW '14). ACM, New York, NY, USA, 487-498.

41. Lee, C. (2005). Between Chaos and Routine: Boundary Negotiating Artifacts in Collaboration. In Proc. of the 2005 European Conference on Computer Supported Cooperative Work, Springer Netherlands, p. 387-406.

42. Luff, P. and C. Heath (1998): Mobility in Collaboration. In S. Poltrock and J. Grudin (eds.): Proceedings of the 1998 ACM conference on Computer Supported Cooperative Work, ACM Press, pp. 305-314.

43. Lynggard, A.B. 2012. Homing Interactions, Aarhus School of Architecture.

44. Malhotra, A. and Van Alstyne, M. 2014. The dark side of the sharing economy ... and how to lighten it. Commun. ACM 57, 11 (October 2014), 24-27.

45. Orr, J. Talking about Machines: An Ethnography of a Modern Job. Cornell University Press, 1996.

46. Pagter, J. I. \& Pedersen, M. G. (2008) A Sense of Security in Pervasive Computing-Is the Light on When the Refrigerator Door Is Closed? LNCS pp. 383-388. Springer, Heidelberg.

47. Palen, L. \& Bødker, S. (2007). Don't Get Emotional. In: Peter C., Beale R. (eds.): Affect and Emotion in Human-Computer Interaction. LNCS, vol. 4868. Springer, Heidelberg, pp. 12-22.

48. Palen, L., Salzman, M., Youngs, E.(2001) Discovery and Integration of Mobile Communications in Everyday Life. Personal and Ubiquitous Computing Journal, 5 (2): 109122.

49. Petersen, M.G., Lynggaard, A.B., Krogh, P.G. and Winther. I.W. 2010. Tactics for homing in mobile life: a fieldwalk study of extremely mobile people. In Proceedings of the 12th international conference on Human computer interaction with mobile devices and services (MobileHCI '10). ACM, New York, NY, USA, 265-274.

50. Polli, A.M. Korn, M. and Klokmose, C.N. 2013. Local area artworks: collaborative art interpretation on-site. In Proceedings of the 2013 ACM conference on Pervasive and ubiquitous computing adjunct publication (UbiComp '13 Adjunct). ACM, New York, NY, USA, 79-82.

51. Rossitto, R. and Eklundh, K.S. 2007. Managing work at several places: a case of project work in a nomadic group of students. In Proceedings of the 14th European conference on Cognitive ergonomics: invent! explore! (ECCE '07). ACM, New York, NY, USA, 45-51.

52. Sennett, R. (1998). The Corrosion of Character. The Personal Consequences of Work in the New Capitalism. New York London: W.W. Norton and Co.

53. Sohn, T., Lee, L., Zhang, S., Dearman, D. and Truong, K. 2012. An examination of how households share and coordinate the completion of errands. In Proceedings of the ACM 2012 conference on Computer Supported Cooperative Work (CSCW '12). ACM, New York, NY, USA, $729-738$

54. Star, S. L. and J. R. Griesemer (1989): 'Institutional Ecology, 'Translations' and Boundary Objects: Amateurs and Professionals in Berkeley's Museum of Vertebrate Zoology, 1907-39', Social Studies of Science, vol. 19, no. 3, p. 387-420.

55. Star, S.L. (2010). This is Not a Boundary Object: Reflections on the Origin of a Concept. Science, technology, \& Human Values 35(5): 601-617.

56. Su, N.M. and Mark. G. 2008. Designing for nomadic work. In Proceedings of the 7th ACM conference on Designing interactive systems (DIS '08). ACM, New York, NY, USA, 305-314. 
57. Whittaker, S., D. Frohlich and O. Daly-Jones (1994): Informal workplace communication: what is it like and how might we support it?. In Proceedings of the SIGCHI Conference on Human Factors in Computing Systems. ACM Press, pp. 208.

58. Wiberg, M. and F. Ljungberg (1999): Exploring the Vision of Anytime, Anywhere in the Context of Mobile Work. In Y. Malhotra (ed.): Knowledge Management and Virtual Organizations. Idea Group Publishing.

59. Williams, S. \& Williams, L. 2005 Space invaders: the negotiation of teenage boundaries through the mobile phone. Issue The Sociological Review. Volume 53, Issue 2, pages 314 331, May 2005. 